\title{
Analisis Kesalahan Representasi Simbolik Mahasiswa Pada Soal Geometri Analitik Bidang
}

\author{
${ }^{1}$ Fertilia Ikashaum, Juitaning Mustika, Endah Wulantina, Edo Dwi Cahyo \\ Tadris Matematika, Fakultas Tarbiyah dan IImu Keguruan, IAIN Metro \\ Jl. Ki Hajar Dewantara, 15A, Kota Metro \\ Email:1 1 kashaum@gmail.com
}

Article History:

Received: 06-12-2020; Received in Revised: 10-02-2021; Accepted: 11-02-2021

\begin{abstract}
Symbolic representation is a dominating ability in geometry. The purpose of this study was to determine the written responses of students when representing geometric objects in mathematical equations. The research used a qualitative descriptive method which was carried out on IAIN Metro students. The test instrument used is in the form of questions to measure the ability of students' symbolic representation with indicators presenting visual representations to mathematical equations or expressions representation. The test instrument is in the form of a circle image along with tangents and polar lines which then must be described by students based on what they see in the picture. Based on the research results, it was obtained three types of student symbolic representation mistakes when solving analytic geometry problems
\end{abstract}

Keywords: Symbolic Representation; Analytic Geometry; Student Mistakes.

\begin{abstract}
Abstrak
Representasi simbolik merupakan kemampuan yang penting dikuasai dalam geometri. Tujuan penelitian ini adalah untuk mengetahui kesalahan mahasiswa ketika merepresentasi objek geometri ke dalam persamaan matematika. Penelitian menggunakan metode deskriptif kualitatif yang dilakukan pada mahasiswa IAIN Metro. Instrumen yang digunakan berupa soal untuk mengukur kemampuan representasi simbolik mahasiswa dengan indikator menyajikan representasi visual ke representasi persamaan atau ekspresi matematis. Instrumen tes berupa gambar lingkaran beserta garis singgung dan garis kutubnya yang kemudian harus dideskripsikan oleh mahasiswa berdasarkan apa yang mereka lihat pada gambar tersebut. Hasil penelitian menunjukkan tiga jenis kesalahan mahasiswa yang sering terjadi dalam melakukan representasi simbolik objek geometri, yaitu tidak memahami konsep, kesalahan dalam membaca data yang terdapat pada gambar, serta kesalahan melakukan operasi matematika.
\end{abstract}

Keywords: Representasi Simbolik; Geometri Analitis; Kesalahan Mahasiswa. 


\section{Pendahuluan}

Geometri adalah salah satu materi matematika yang dipelajari sejak sekolah dasar. Geometri memfasilitasi berkembangnya kemampuan pemecahan masalah melalui interaksi hasil dari pengalaman belajar dan penalaran deduktif ${ }^{1}$. Dalam perguruan tinggi, geometri bidang dan geometri ruang menjadi mata kuliah prasyarat bagi beberapa mata kuliah lain. Ini menunjukkan peran geometri dalam membangun integrasi terhadap bidang matematika lainnya ${ }^{2}$. Namun sayangnya terdapat masalah dalam memahami geometri antara lain visualisasi objek geometri tidak biasa ditampilkan dalam pembelajaran ${ }^{3}$. Hal ini menyebabkan pemahaman mahasiswa terhadap objek geometri tidak maksimal.

Keadaan di lapangan, setelah dilakukan pra survey dengan memberi soal penyajian kembali bentuk gambar ke persamaan matematis pada materi garis lurus diketahui bahwa sebagian mahasiswa kurang menguasai materi ini. Kesalahan yang paling sering dilakukan adalah kurangnya kemampuan mahasiswa dalam mengolah gambar menjadi bentuk persamaan matematis yang diinginkan. Dari kajian literatur 456, diduga bahwa kurangnya penguasaan mahasiswa disebabkan oleh kesalahan dalam mendeskripsikan bangun geometri ke dalam bentuk persamaan atau ekspresi matematis. Dengan kata lain kemampuan mahasiswa dalam merepresentasikan suatu masalah matematika ke dalam bentuk representasi lain belum optimal.

1 Preety N Tripathi, "Exploring the Use of Deductive Logic in Geometry As," in International Conference to Review Research in Science, Technology and Mathematics Education, 2020, 91-100.

2 Nurul Asma and M Ikhsan, "Pengembangan Perangkat Pembelajaran Geometri Dengan Pendekatan Realistic Mathematics Education (RME) Berbantuan Cabri 3D," Jurnal Peluang 7, no. 1 (2019): 86-93, https://doi.org/10.24815/jp.v7i1.13740.

${ }^{3}$ Fertilia Ikashaum, Kartika Sari Dewi, and Lena Wahyuni, "Analisis Kebutuhan Bahan Ajar Geometri Berbantuan Aplikasi Komputer,” Jurnal Komputasi 7, no. 2 (2019): 38-42.

${ }^{4}$ Aritsya Imswatama and Nur'aini Muhassanah, "Analisis Kesalahan Mahasiswa Dalam Menyelesaikan Soal Geometri Analitik Bidang Materi Garis Dan Lingkaran," Suska Journal of Mathematics Education 2, no. 1 (2016): 1, https://doi.org/10.24014/sjme.v2i1.1368.

5 Damianus Dao Samo, "Kemampuan Pemecahan Masalah Matematika Mahasiswa Tahun Pertama Dalam Memecahkan Masalah Geometri Konteks Budaya," Jurnal Riset Pendidikan Matematika 4, no. 2 (2017): 141, https://doi.org/10.21831/jrpm.v4i2.13470.

${ }^{6}$ Rita Novita et al., "Penyebab Kesulitan Belajar Geometri Dimensi Tiga," Jurnal Riset Pendidikan Matematika 5, no. 1 (2018): 18, https://doi.org/10.21831/jrpm.v5i1.16836. 
Representasi bertujuan untuk mengkomunikasikan pendekatan matematika sehingga memunculkan pemahaman terhadap dirinya dan orang lain ${ }^{7}$. Dalam pembelajaran geometri penguasaan kemampuan representasi menjadi hal yang wajib dikuasai oleh mahasiswa 8 . Objek visual dalam geometri menjadi alat yang dapat mendukung pemahaman konseptual dari suatu ide matematika 9 . Melalui penguasaan representasi, pemodelan matematika beserta penyelesaian masalah matematika dapat diperoleh lebih mudah. Selain itu, kemampuan representasi membantu mengembangkan dan memperdalam pemahaman mahasiswa tentang konsep matematika ${ }^{10}$. Dengan demikian, mahasiswa yang sedang belajar menjadi calon guru harus memiliki kemampuan representasi matematis yang baik ${ }^{11}$. Hal ini bertujuan untuk memfasilitasi peserta didiknya kelak dalam merepresentasikan sebuah ide matematis.

Representasi secara umum digolongkan menjadi representasi visual, representasi simbolik, dan representasi verbal ${ }^{12}$. Representasi visual terdiri dari representasi dalam bentuk tabel, gambar, atau diagram/grafik. Representasi visual berkaitan erat dengan representasi simbol berupa penggunaan persamaan dan ekspresi aljabar 13. Pada materi geometri, pemakaian gambar dan ekspresi aljabar menjadi komponen utama yang menunjang pembelajaran. Dengan demikian, penyajian kembali bentuk gambar ke dalam bentuk persamaan atau ekspresi matematis maupun sebaliknya menjadi kemampuan yang menunjang keberhasilan mahasiswa pada materi ini.

${ }^{7}$ Argi Ayu et al., "Analisis Kesalahan Kemampuan Representasi Matematis Pada Model Pembelajaran Think-Talk-Write Dengan Verbal Feedback," in PRISMA, Prosiding Seminar Nasional Matematika, vol. 3, 2020, 518-20.

8 Budi Hari Priyanto and Mokhammad Ridwan Yudhanegara, "Peran Bahan Ajar Berbasis Teori Van Hiele Pada Kemampuan Representasi Matematis Siswa," in Sesiomadika: Prosiding Seminar Nasional Matematika Dan Pendidikan Matematika, 2018, 343-51.

${ }_{9}^{9}$ Mile Krajcevski and Ruthmae Sears, "Common Visual Representations as a Source for Misconceptions of Preservice Teachers in a Geometry Connection Course," International Journal of Mathematics Teaching and Learning 20, no. 1 (2019): 85.

10 Yuliana Ina Kii, "Analysis of Representation Forms on Linear Equations System Two Variables ( LESTV ) Materials for Class VIII Junior High School” 2019, no. July 2019 (2020): 85-91, https://doi.org/10.24071/seadr.2019.12.

11 Erni Puji Astuti, "Representasi Matematis Mahasiswa Calon Guru Dalam Menyelesaikan Masalah Matematika," Beta Jurnal Tadris Matematika 10, no. 1 (2017): 70, https://doi.org/10.20414/betajtm.v10i1.100.

12 Gusti Firda Khairunnisa, Abdur Rahman, and Hery Susanto, "Keberhasilan Siswa Dalam Menyelesaikan Soal Cerita Berdasarkan Kemampuan Membuat Berbagai Representasi Matematis," Jurnal Pendidikan Universitas Negeri Malang 3, no. 6 (2018): 723-30.

13 Anggiana Putri Aliyanti, Octavina Rizky Utami Putri, and Zukhrufurrohmah Zukhrufurrohmah, "Analisis Kesalahan Representasi Simbolik Mahasiswa Dalam Menyelesaikan Soal High Order Thinking Skill," AKSIOMA: Jurnal Program Studi Pendidikan Matematika 8, no. 3 (2019): 382, https://doi.org/10.24127/ajpm.v8i3.2265. 
Penelitian yang dilakukan oleh Yudhanegara dan Lestari ${ }^{14}$ menunjukkan bahwa mahasiswa mengalami kesulitan dalam representasi ekspresi matematis, yaitu membuat gambar persamaan atau model matematis dari representasi lain yang diberikan. Hal serupa ditunjukkan oleh Astuti ${ }^{15}$ yang juga menyatakan bahwa mahasiswa calon guru matematika perlu memiliki kemampuan representasi yang baik dalam hal membuat persamaan atau model matematis untuk memfasilitasi penyelesaian masalah. Aliyanti, dkk 16 memaparkan hasil penelitiannya yang menunjukkan kesalahan representasi simbolik mahasiswa terjadi antara lain karena ketidak telitian dalam membaca soal, tidak memahami konsep materi, dan tidak memahami definisi simbol yang digunakan.

Dugaan terhadap kurangnya pemahaman representasi bangun geometri ke dalam bentuk simbolik berupa persamaan atau ekspresi aljabar berdasarkan hasil pra survey mendorong kebutuhan untuk melakukan penelitian terhadap jenis-jenis kesalahan representasi simbolik mahasiswa agar dapat dilakukan upaya untuk memperbaiki kesalahan tersebut. Oleh karena itu, artikel ini bertujuan untuk mendeskripsikan kesalahan representasi simbolik mahasiswa dalam menyelesaikan soal geometri analitik bidang sub materi lingkaran. Hasil dari penelitian ini diharapkan dapat memberikan kontribusi tentang jenis-jenis kesalahan representasi yang pada umumnya dialami mahasiswa dalam pembelajaran Geometri Analitik Bidang.

\section{Metode}

Penelitian ini menggunakan pendekatan kualitatif dengan jenis penelitian deskriptif. Metode yang digunakan adalah studi kasus dengan subjek penelitian diambil dari 34 orang mahasiswa jurusan Tadris Matematika yang menempuh mata kuliah geometri analitik bidang.

Prosedur penelitian diawali dengan menentukan permasalahan berdasarkan hasil observasi, yaitu banyaknya mahasiswa yang melakukan kesalahan dalam melakukan representasi objek geometri ke dalam persamaan matematika. Tahapan selanjutnya adalah melakukan studi literatur terkait kesalahan yang terjadi dalam merepresentasi objek geometri. Tahap ketiga dari penelitian ini adalah menentukan subjek penelitian. Tahap keempat yaitu melakukan kajian dari hasil penelitian terdahulu yang relevan dan studi

14 Mokhammad Ridwan Yudhanegara and Karunia Eka Lestari, “Analisis Kemampuan Representasi Matematis Mahasiswa Pada Mata Kuliah Geometri Transformasi Berdasarkan Latar Belakang Pendidikan Menengah," Jurnal Matematika Integratif 13, no. 1 (2017): 29, https://doi.org/10.24198/jmi.v13.n1.11410.29-34.

15 Astuti, "Representasi Matematis Mahasiswa Calon Guru Dalam Menyelesaikan Masalah Matematika."

16 Aliyanti, Putri, and Zukhrufurrohmah, "Analisis Kesalahan Representasi Simbolik Mahasiswa Dalam Menyelesaikan Soal High Order Thinking Skill." 
pendahuluan berupa observasi selama pembelajaran berlangsung. Tahap kelima adalah menetapkan metode pengumpulan data yaitu berupa soal pada materi lingkaran. Tahap keenam yaitu analisis data dengan mengidentifikasi jenis kesalahan representasi simbolik apa saja yang dilakukan oleh mahasiswa. Tahap ketujuh yaitu mendeskripsikan hasil penelitian.

Tes yang digunakan pada penelitian ini berupa tes kemampuan representasi simbolik mahasiswa dengan indikator menyajikan kembali representasi gambar ke representasi persamaan atau ekspresi matematis. Tes berupa serangkaian gambar lingkaran beserta garis singgung dan garis kutubnya yang kemudian harus dideskripsikan oleh mahasiswa berdasarkan apa yang mereka lihat pada Gambar 1.

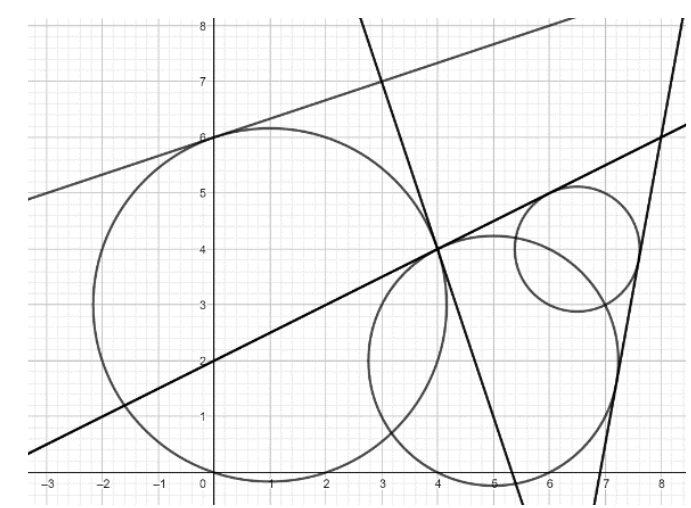

Gambar 1. Instrumen Tes Representasi

Tes ini bertujuan untuk memperoleh respon tertulis subjek penelitian dalam merepresentasi objek geometri ke dalam persamaan matematika. Analisis data kemudian disajikan dalam bentuk deskripsi. Peninjauan kembali hasil penelitian dilakukan pula dari hasil penelitian terdahulu.

\section{Hasil dan Diskusi}

Berdasarkan hasil tes pada soal lingkaran, jawaban mahasiswa dapat dikelompokkan menjadi tiga jenis, yaitu tidak memahami konsep, kesalahan dalam membaca data yang terdapat pada Gambar 2, serta kesalahan melakukan operasi matematika. 


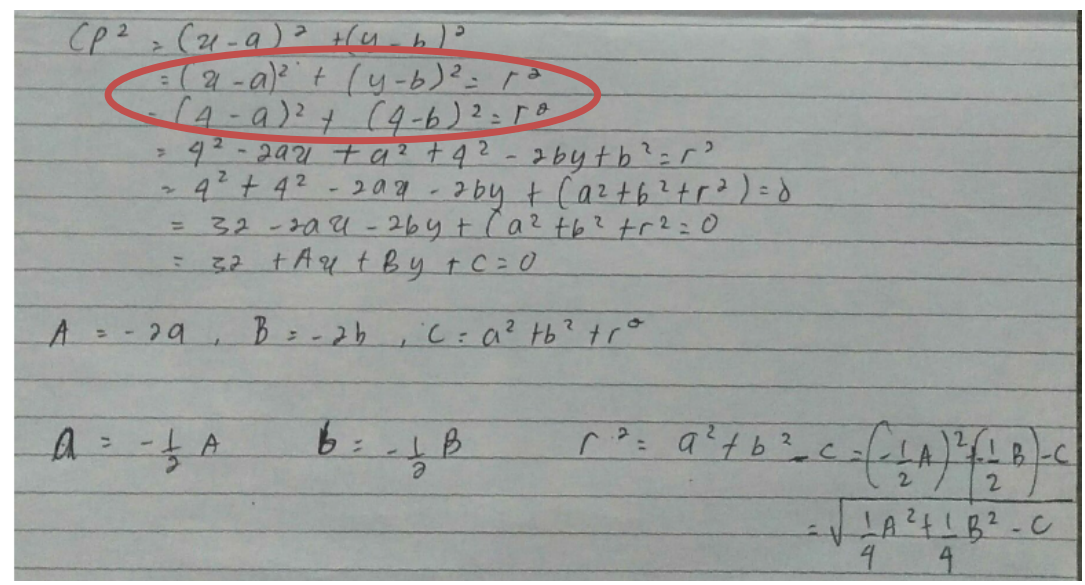

Gambar 2. Substitusi Titik Sebagai Pusat Lingkaran

Berdasarkan Gambar 2 terlihat bahwa mahasiswa melakukan kesalahan dalam substitusi titik pusat. Representasi yang benar adalah melakukan substitusi variabel a dan b dengan angka titik pusat, sedangkan pada gambar di atas, titik pusat disubstitusi pada variabel $x$ dan $y$. Terlebih lagi, titik $(4,4)$ bukan merupakan titik pusat lingkaran yang dimaksud pada soal. Karena kesalahan ini, mahasiswa menjadi bingung dalam menjabarkan perhitungan rumus hingga akhirnya tidak menemukan solusi yang diinginkan.

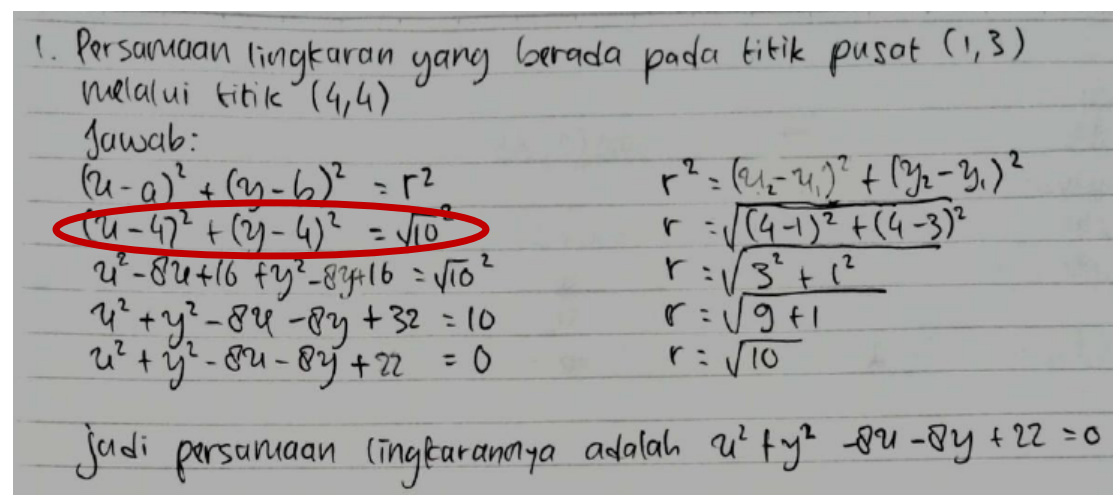

Gambar 3. Pengambilan Titik Pusat Lingkaran

Berdasarkan Gambar 3 terlihat bahwa mahasiswa menentukan titik $(1,3)$ sebagai titik pusat dan titik $(4,4)$ sebagai titik yang berada pada lingkaran. Saat melakukan substitusi ke dalam persamaan umum lingkaran, ia melakukan kesalahan dalam menempatkan titik pusat sebagai titik pada lingkaran. Meskipun ia menghitung panjang jari-jari lingkaran dengan benar, saat menjabarkan perhitungan, hasil akhir persamaan lingkaran menjadi salah. 

Maret-2021, Vol.9, No.1, hal.57-68

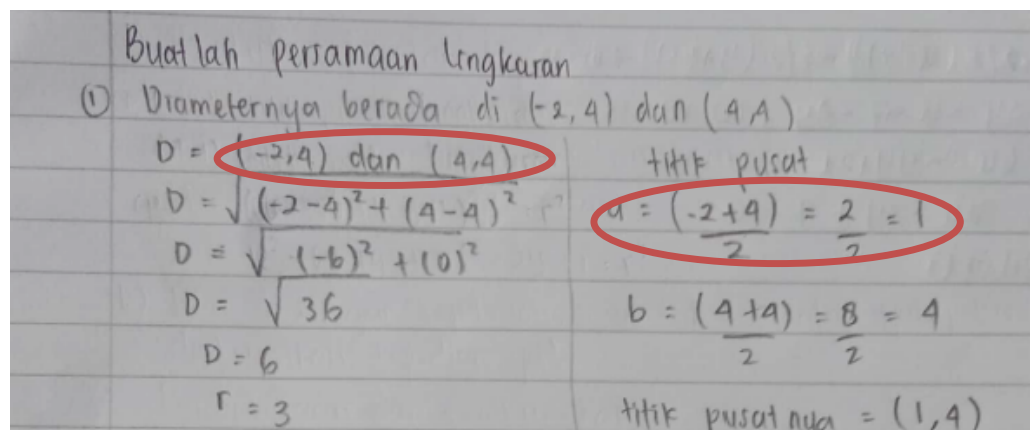

Gambar 4. Pengambilan Titik Sebagai Diameter

Berdasarkan Gambar 4 terlihat bahwa mahasiswa membuat persamaan lingkaran menggunakan panjang jari-jari, namun terdapat kesalahan dalam pengambilan dua buah titik yang akan dijadikan diameter. Kesalahan ini mengakibatkan panjang jari-jari lingkaran tidak diperoleh dengan benar sehingga persamaan lingkaran juga tidak tepat. Pengambilan titik yang benar seharusnya titik $(-2,2)$ dan $(4,4)$; titik $(0,6)$ dan $(2,0)$; atau titik $(-2,4)$ dan $(4,2)$. Dampak lain dari kesalahan pengambilan titik sebagai diameter adalah kesalahan perhitungan titik pusat. Ketika dua titik yang dipilih bukan sebagai diameter, maka titik tengahnya juga bukan merupakan titik pusat lingkaran.

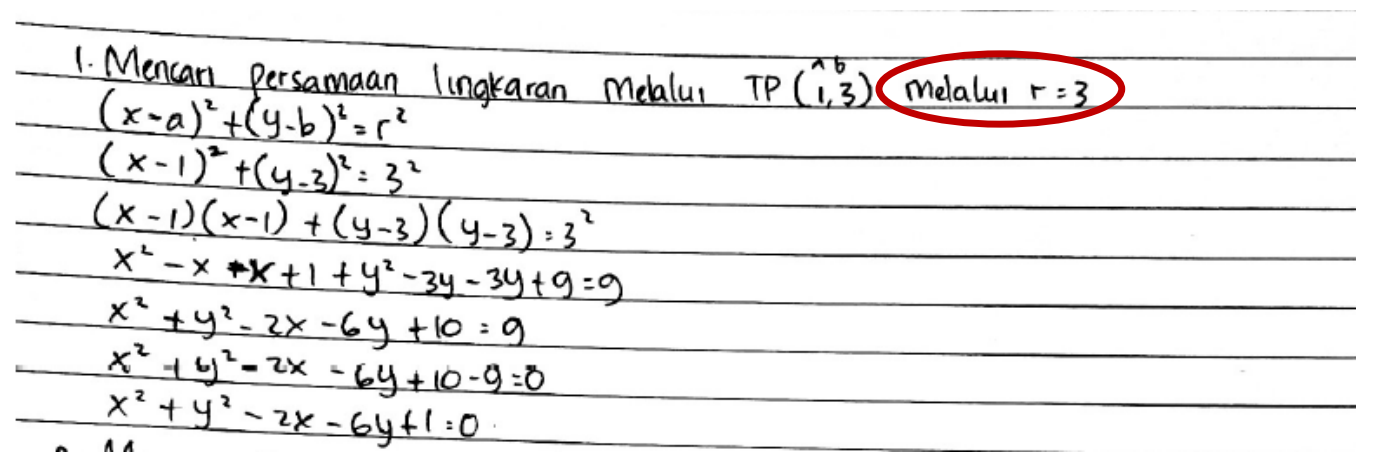

Gambar 5. Menentukan Panjang Jari-Jari Lingkaran

Berdasarkan Gambar 5 mahasiswa akan mencari persamaan lingkaran menggunakan titik pusat dan jari-jari. Ia menentukan titik $(1,3)$ sebagai titik pusat lingkaran, dan menentukan jari-jari lingkaran sepanjang 3 satuan. Jarijari tersebut ia tentukan tanpa melakukan perhitungan terlebih dahulu. Ketika melakukan substitusi ke dalam persamaan lingkaran, hasil yang diperoleh bukan merupakan persamaan lingkaran yang diinginkan. 


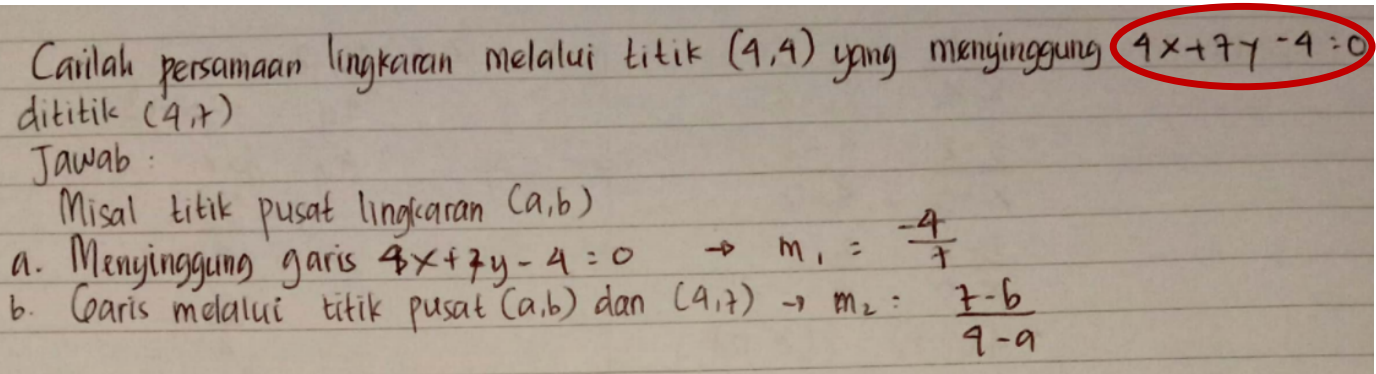

\section{Gambar 6. Menentukan Persamaan Garis}

Berdasarkan Gambar 6 mahasiswa menentukan persamaan garis tanpa menghitungnya. Jika lingkaran melalui titik $(4,4)$ maka terdapat dua garis yang melalui titik tersebut, yaitu $3 x+y=16$ dan $2 y-x=4$. Namun, kedua garis tersebut tidak melalui titik $(4,7)$. Sehingga tidak terdapat konsistensi antara titik dan persamaan garis yang ia ambil dengan caranya menentukan persamaan lingkaran.

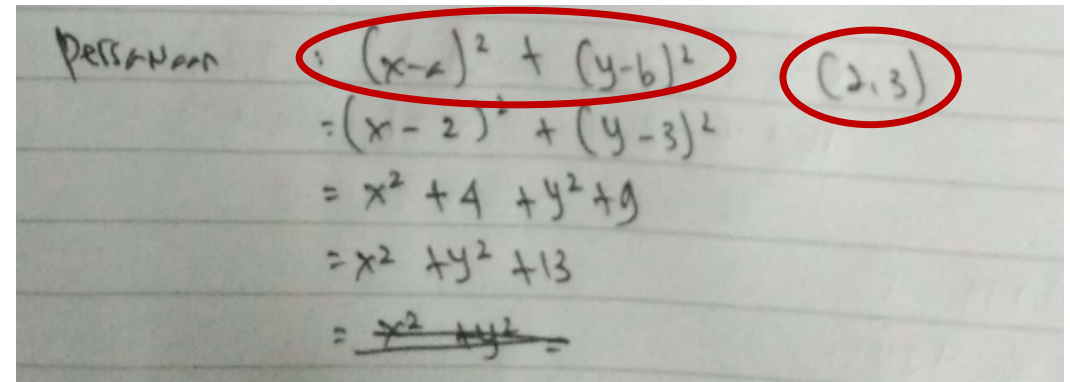

Gambar 7. Kesalahan dalam membaca gambar

Berdasarkan Gambar 7 mahasiswa melakukan kesalahan dalam membaca gambar yang ada pada soal. Kesalahan tersebut terlihat dari pengambilan titik yang bukan merupakan pusat lingkaran; substitusi titik pusat ke persamaan umum lingkaran; dan penjabaran persamaan lingkaran ke dalam bentuk persamaan umum lingkaran yang lain. Dari jawaban tersebut terlihat ia tidak menuliskan persamaan lingkaran dengan lengkap. 


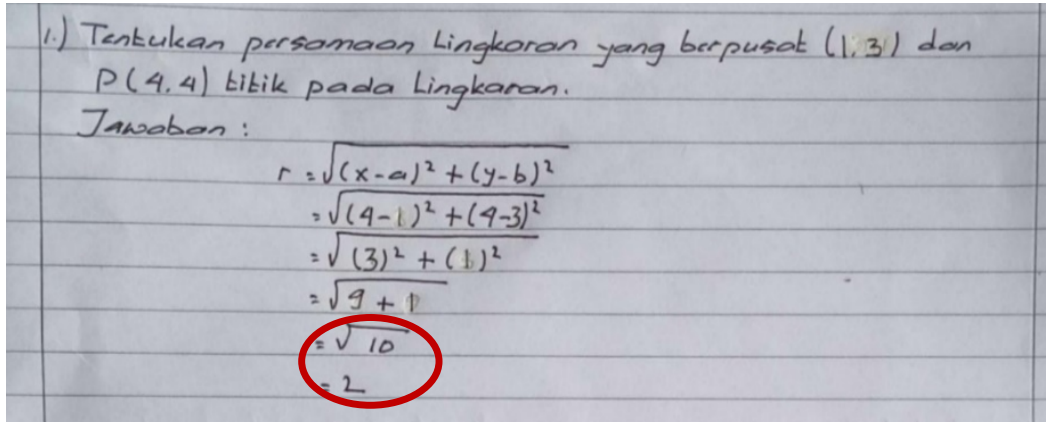

Gambar 8. Kesalahan melakukan perhitungan

Berdasarkan Gambar 8 mahasiswa menetapkan titik $(1,3)$ sebagai titik pusat dan titik $(4,4)$ sebagai titik yang dilalui lingkaran. Hal yang pertama ia lakukan adalah mencari jari-jari lingkaran menggunakan dua titik tersebut. Kesalahan yang ia lakukan adalah menyederhanakan bilangan irasional menjadi bilangan bulat. Karena panjang jari-jari tidak benar, maka persamaan lingkaran selanjutnya menjadi tidak benar juga.

Secara garis besar kesalahan yang dibuat mahasiswa dapat dibagi kedalam tiga jenis, yaitu kesalahan dalam memahami konsep; kesalahan membaca data; dan kesalahan dalam melakukan perhitungan. Gambar 1 dan 2 menunjukkan kurangnya pemahaman mahasiswa terhadap konsep lingkaran dan keterampilan prasyarat, Gambar 3, 4, 5, dan 6 merupakan kesalahan mahasiswa dalam membaca data, sedangkan Gambar 7 merupakan kesalahan dalam melakukan perhitungan.

Kesalahan mahasiswa dalam melakukan substitusi variabel ke dalam persamaan matematika disebabkan kurangnya penguasaan konsep dan keterampilan prasyarat. Jenis kesalahan ini menghalangi mahasiswa menemukan solusi meskipun memperoleh informasi yang benar dari soal. Ketidakmampuan mahasiswa dalam menguasai prasyarat dasar meliputi ketidaktahuan tentang algoritma, penguasaan konsep dasar yang tidak memadai, prosedur yang salah dalam menerapkan teknik matematika, dan informasi yang tidak memadai tentang konsep dan simbol yang diperlukan ${ }^{17}$. Pemahaman terhadap konsep variabel juga menjadi kunci berjalannya proses matematika agar perannya terhadap hasil pembelajaran terlibat dalam variasi penerapan variabel yang lebih kompleks ${ }^{18}$.

Variasi kesalahan yang paling banyak dilakukan mahasiswa adalah kesalahan dalam membaca data. Beberapa kesalahan ini berupa kekeliruan siswa dalam menentukan titik pusat lingkaran, melakukan pembulatan terhadap panjang jari-jari lingkaran, dan merepresentasikan garis ke dalam

17 Hendrik Radatz, "Error Analysis in Mathematics Education," Journal for Research in Mathematics Education 10, no. 3 (2020): 163-72, https://doi.org/10.5951/jresematheduc.10.3.0163.

18 B.S Bloom, Human Characteristics and School Learning. (McGraw-Hill, 1976). 
persamaan matematika. Dalam matematika, keterampilan membaca data sangat penting dalam proses memahami masalah ${ }^{19}$. Keterampilan membaca data sebagai informasi awal diperlukan untuk menafsirkan dan mengolah informasi. Kesulitan mahasiswa melakukan representasi simbolik berasal dari kurangnya kurangnya pengetahuan mereka tentang arti simbol dan tanda yang digunakan 20. Padahal, interpretasi simbol yang muncul menjadi landasan untuk melakukan representasi terhadap persamaan matematika. Proses matematis dapat berjalan setelah representasi simbolik selesai dilakukan.

Sebagian besar sumber kesalahpahaman adalah generalisasi yang berlebihan dari pengetahuan sebelumnya. Persepsi yang awalnya benar, ketika diteruskan ke domain tambahan menjadi salah 21. Agar dapat melakukan perhitungan dengan baik, mahasiswa perlu memahami lebih dahulu konsep variabel. Kesalahan beruntun dapat terjadi ketika kemampuan prasyarat ini tidak dipenuhi. Oleh karena itu, jawaban yang dijabarkan menunjukkan mahasiswa tidak teliti dalam melakukan operasi matematika

\section{Kesimpulan}

Hasil dari analisis ini menunjukkan tiga jenis kesalahan mahasiswa yang sering terjadi dalam melakukan representasi simbolik objek geometri, yaitu tidak memahami konsep, kesalahan dalam membaca data yang terdapat pada gambar, serta kesalahan melakukan operasi matematika. Salah satu upaya yang dapat dilakukan untuk meminimalisir kesalahan tersebut adalah membiasakan mahasiswa untuk melakukan berbagai macam representasi. Hasil dari penelitian ini dapat menjadi acuan bagi dosen untuk lebih memfokuskan bentuk representasi simbolik pada pembelajaran geometri.

19 Tarzimah Tambychik and Thamby Subahan Mohd Meerah, "Students' Difficulties in Mathematics Problem-Solving: What Do They Say?," Procedia - Social and Behavioral Sciences 8, no. 5 (2010): 142-51, https://doi.org/10.1016/j.sbspro.2010.12.020.

20 Adem Duru and Onder Koklu, "Middle School Students' Reading Comprehension of Mathematical Texts and Algebraic Equations," International Journal of Mathematical Education in Science and Technology 42, no. 4 (2011): 447-68, https://doi.org/10.1080/0020739X.2010.550938.

21 Alwyn Olivier, "Handling Pupils ' Misconceptions," Mathematics Education for PreService and In-Service, no. July (1992): 193-209. 


\section{Daftar Pustaka}

Aliyanti, Anggiana Putri, Octavina Rizky Utami Putri, and Zukhrufurrohmah Zukhrufurrohmah. "Analisis Kesalahan Representasi Simbolik Mahasiswa Dalam Menyelesaikan Soal High Order Thinking Skill." AKSIOMA: Jurnal Program Studi Pendidikan Matematika 8, no. 3 (2019): 382. https://doi.org/10.24127/ajpm.v8i3.2265.

Asma, Nurul, and M Ikhsan. "Pengembangan Perangkat Pembelajaran Geometri Dengan Pendekatan Realistic Mathematics Education (RME) Berbantuan Cabri 3D." Jurnal Peluang 7, no. 1 (2019): 86-93. https://doi.org/10.24815/jp.v7i1.13740.

Astuti, Erni Puji. "Representasi Matematis Mahasiswa Calon Guru Dalam Menyelesaikan Masalah Matematika." Beta Jurnal Tadris Matematika 10, no. 1 (2017): 70. https://doi.org/10.20414/betajtm.v10i1.100.

Ayu, Argi, Sulistyani Kusumaningtyas, Tri Sri, and Noor Asih. "Analisis Kesalahan Kemampuan Representasi Matematis Pada Model Pembelajaran Think-Talk-Write Dengan Verbal Feedback." In PRISMA, Prosiding Seminar Nasional Matematika, 3:518-20, 2020.

Bloom, B.S. Human Characteristics and School Learning. McGraw-Hill, 1976.

Duru, Adem, and Onder Koklu. "Middle School Students' Reading Comprehension of Mathematical Texts and Algebraic Equations." International Journal of Mathematical Education in Science and Technology 42, no. 4 (2011): $447-68$. https://doi.org/10.1080/0020739X.2010.550938.

Ikashaum, Fertilia, Kartika Sari Dewi, and Lena Wahyuni. "Analisis Kebutuhan

Bahan Ajar Geometri Berbantuan Aplikasi Komputer." Jurnal Komputasi 7, no. 2 (2019): 38-42.

Imswatama, Aritsya, and Nur'aini Muhassanah. "Analisis Kesalahan Mahasiswa Dalam Menyelesaikan Soal Geometri Analitik Bidang Materi Garis Dan Lingkaran." Suska Journal of Mathematics Education 2, no. 1 (2016): 1. https://doi.org/10.24014/sjme.v2i1.1368.

Khairunnisa, Gusti Firda, Abdur Rahman, and Hery Susanto. "Keberhasilan Siswa Dalam Menyelesaikan Soal Cerita Berdasarkan Kemampuan Membuat Berbagai Representasi Matematis." Jurnal Pendidikan Universitas Negeri Malang 3, no. 6 (2018): 723-30.

Kii, Yuliana Ina. "Analysis of Representation Forms on Linear Equations System Two Variables ( LESTV ) Materials for Class VIII Junior High School" 2019, no. July 2019 (2020): 85-91. https://doi.org/10.24071/seadr.2019.12.

Krajcevski, Mile, and Ruthmae Sears. "Common Visual Representations as a Source for Misconceptions of Preservice Teachers in a Geometry Connection Course." International Journal of Mathematics Teaching and Learning 20, no. 1 (2019): 85.

Novita, Rita, Rully Charitas Indra Prahmana, Nurul Fajri, and Mulia Putra. "Penyebab Kesulitan Belajar Geometri Dimensi Tiga." Jurnal Riset $\begin{array}{llllll}\text { Pendidikan Matematika 5, no. } 1 & 1 & \text { (2018): } & 18 .\end{array}$ https://doi.org/10.21831/jrpm.v5i1.16836.

Olivier, Alwyn. "Handling Pupils ' Misconceptions." Mathematics Education for 

Maret-2021, Vol.9, No.1, hal.57-68

Pre-Service and In-Service, no. July (1992): 193-209.

Priyanto, Budi Hari, and Mokhammad Ridwan Yudhanegara. "Peran Bahan Ajar Berbasis Teori Van Hiele Pada Kemampuan Representasi Matematis Siswa." In Sesiomadika: Prosiding Seminar Nasional Matematika Dan Pendidikan Matematika, 343-51, 2018.

Radatz, Hendrik. "Error Analysis in Mathematics Education." Journal for Research in Mathematics Education 10, no. 3 (2020): 163-72. https://doi.org/10.5951/jresematheduc.10.3.0163.

Samo, Damianus Dao. "Kemampuan Pemecahan Masalah Matematika Mahasiswa Tahun Pertama Dalam Memecahkan Masalah Geometri Konteks Budaya." Jurnal Riset Pendidikan Matematika 4, no. 2 (2017): 141. https://doi.org/10.21831/jrpm.v4i2.13470.

Tambychik, Tarzimah, and Thamby Subahan Mohd Meerah. "Students' Difficulties in Mathematics Problem-Solving: What Do They Say?" Procedia - Social and Behavioral Sciences 8, no. 5 (2010): 142-51. https://doi.org/10.1016/j.sbspro.2010.12.020.

Tripathi, Preety N. "Exploring the Use of Deductive Logic in Geometry As." In International Conference to Review Research in Science, Technology and Mathematics Education, 91-100, 2020.

Yudhanegara, Mokhammad Ridwan, and Karunia Eka Lestari. "Analisis Kemampuan Representasi Matematis Mahasiswa Pada Mata Kuliah Geometri Transformasi Berdasarkan Latar Belakang Pendidikan Menengah." Jurnal Matematika Integratif 13, no. 1 (2017): 29. https://doi.org/10.24198/jmi.v13.n1.11410.29-34. 